\title{
Ultrason Eşliğinde Diferansiyel Üst Ekstremite Bloğu Deneyimlerimiz: Retrospektif Gözlemsel Araştırma
}

\author{
Ultrasound Guided Upper Extremity Differential Block: A Retrospective \\ Observational Study \\ Onur Balaban
}

Dumlupınar Üniversitesi Tıp Fakültesi, Anesteziyoloji ve Reanimasyon AD. Kütahya, Türkiye

Yazışma Adresi / Correspondence:

Onur Balaban

Dumlupinar University Hospital, Department of Anesthesiology and Pain Medicine

Evliya Celebi Mh. 43040 Merkez/Kutahya

T: +902742316660Ｅ-mail: obalabandr@gmail.com

Geliş Tarihi / Received : 24.05.2018 Kabul Tarihi / Accepted : 10.09.2018

\footnotetext{
$\ddot{0} z$

Amaç Diferansiyel blok, sinirin sensoryal ve motor aktivitesinin ayrı ayrı inhibisyonu olarak tanımlanır. Diferansiyel periferik sinir bloklarında motor aktivitenin korunması ve sensoryal aktivitenin inhibisyonu amaçlanı. Bu sayede intraoperatif olarak tendon ve kasların hareketlerinin incelenmesi mümkündür. Bu çalışmada kliniğimizde gerçekleştirdiğimiz ultrason eşliğinde diferansiyel üst ekstremite bloğu yapılan hastaların retrospektif değerlendirilmesi ve deneyimlerimizin sunulması amaçlandı. ( Sakarya Tıp Dergisi, 2018, 8(3):650-656 )

Gereç ve Dumlupınar Üniversitesi Evliya Çelebi Hastanesi'nde Mart 2016 - Nisan 2018 arasında \% 0,5 prilokain ile diferansiyel blok amaçlı ultrason Yöntem eşliğinde infraklavikular brakiyal pleksus bloğu yapılan hastaların anestezi kayıtları değerlendirildi. Hastaların demografik verileri, blok uygulama endikasyonları, blok başlangıç zamanı, operasyon süresi, intraoperatif-postoperatif komplikasyon varlığı incelendi. Duyusal blok, 0 ile 2 arasında, motor blok, 0 ile 5 arasında sayısal ölçek kullanılarak değerlendirildi.

Bulgular Çalışma, dahil edilme kriterlerini karşılayan 43 hasta (24 kadın, 19 erkek) ile yapıldı. Ortalama operasyon süresi 47,5 $\pm 20,71$ dakikaydı. Diferansiyel brakiyal pleksus bloğu elde etmek için ortalama 19,53 $\pm 3,04 \mathrm{ml} \% 0.5^{\prime}$ lik prilokain kullanıldı. Medyan motor blok skoru 3 (1-5) idi. 41 olguda motor fonksiyon yeterliydi, 2 olguda motor blok skoru 1'di ve peroperatif motor fonksiyon yeterli değildi. Olguların hiçbirinde allerjik reaksiyon, intraoperatif ve postoperatif komplikasyon gelişmedi.

Sonuç Kliniğimizde, üst ekstremite yumuşak doku operasyonlarında \% 0,5 prilokain ile diferansiyel brakiyal pleksus bloğu başarıyla gerçekleştirilmiştir. Prilokaine ait yan etkiler görülmemiştir.

Anahtar Diferansiyel blok; infraklavikular blok; prilokain; ultrason

Kelimele
}

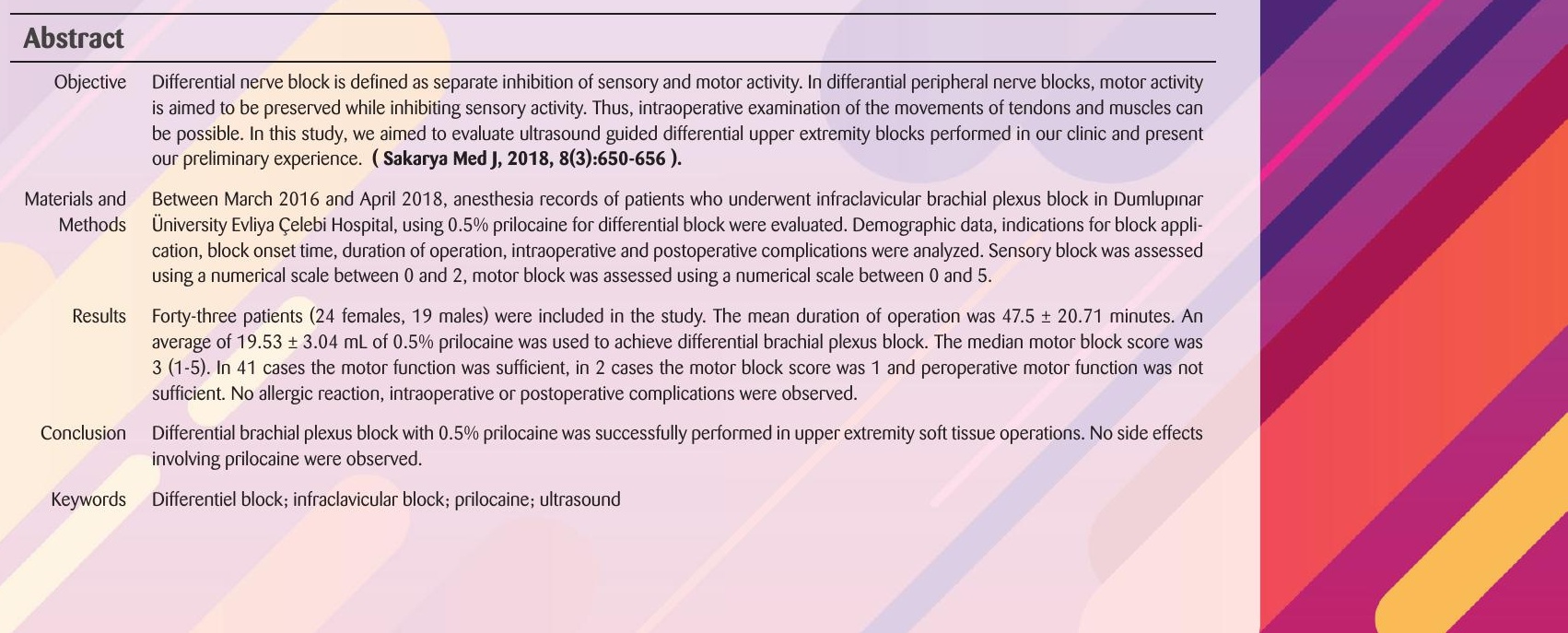


Sakarya Tnp Dergisi 2018;8(3):650-656

\section{Giriş}

Diferansiyel nöral blok, sensoryal ve motor aktivitenin ayrı ayrı inhibisyonu olarak tanımlanır. Dilüe ve düşük dozda lokal anestezikler kullanılarak motor aktivitede kısıtlama olmadan hastanın analjezisinin sağlanması amaçlanmaktadır., ${ }^{1,2}$

Üst ekstremite bloklarında ise diferansiyel bloklar yeni tanımlanmaktadır. Genellikle sensoryal inhibisyon ve motor aktivitenin korunması istenmektedir. Diferansiyel nöral blokların, hem cerrahi anestezi sağlaması hem de cerrahi müdahaleyi kolaylaştıracak bir ortam sağlaması beklenir. Bu sayede, intraoperatif olarak tendon ve kasların hareketlerinin incelenebilir. Aktif hareketin intraoperatif olarak gözlemlenmesi tendonların cerrahi onarımını kolaylaştırmaktadır. Tenolizde, fleksör tendon onarımında ve tendon transferlerindeki gerginliğin ayarlanmasında kas ve tendon hareketlerinin görülmesi önemli ve faydalıdır. ${ }^{3} \mathrm{Bu}$ amaçla el cerrahisinde yüksek doz lokal anestezik infiltrasyonu uygulamasıyla, motor blok oluşturmadan "wide awake” lokal anestezi yöntemi kullanılmaktadır. ${ }^{4}$ Diferansiyel periferik sinir blokları, "wide awake" anestezi tekniğine iyi bir alternatif olabilir.

Periferik sinir bloklarında cerrahi anestezi elde etmek için önerilen lokal anestezik konsantrasyonları, motor bloğa da neden olur. Rejyonal anestezide ultrason kullanımı, periferik sinir bloğu için kullanılan lokal anestezik dozunun azaltılmasına katkıda bulunmuştur., ${ }^{5,6}$ Prilokain, kısa etkili bir amid tipi lokal anesteziktir ve diferansiyel blok uygulaması için uygun bir seçim olabilir. Prilokain, tek başına veya farklı dozlarda başka lokal anestetiklerle karıştırılarak periferik sinir blokları için başarıyla kullanılmıştır. ${ }^{7,8}$ Tek başına düşük doz prilokainin ultrason rehberliği altında uygulanması ile motor aktivite engellenmeden duyusal anestezi sağlanabilir. Kliniğimizde, diferansiyel blok oluşturmak amaçlı \% 0,5 konsantrasyonda prilokain ile ultrason eşliğinde infraklavikular blok uygulamasıyla üst ekstremite yumuşak doku operasyonlarını gerçekleştirmekteyiz.

Bu çalışmada kliniğimizde gerçekleştirdiğimiz ultrason eşliğinde diferansiyel üst ekstremite bloğu yapılan hastaların retrospektif olarak değerlendirilmesi ve deneyimlerimizin sunulması amaçlandı.

\section{Gereç ve Yöntemler}

Bu çalışma tanımlayıcı tipte bir araştırmadır. Çalışma için yerel etik kuruldan onam alındı. Diferansiyel blok, düşük konsantrasyon ve volümde prilokain kullanılarak ultrason eşliğinde yapılan infraklavikular blok ve motor aktivite korunarak sensoryal blok elde edilmesi olarak tanımlandı.

\section{Hasta seçimi:}

Kliniğimizde üst ekstremitede yumuşak doku operasyonu geçirecek olan erişkin (18-85 yaş) hastalara diferansiyel periferik sinir bloğu uygulanmaktadır. Dumlupınar Üniversitesi Evliya Çelebi Hastanesi'nde Mart 2016 ve Nisan 2018 arasında ultrason eşliğinde diferansiyel üst ekstremite bloğu uygulanan hastaların dosyaları ve anestezi kayıtları retrospektif olarak incelendi.

\section{Blok Uygulaması:}

Kliniğimizde diferansiyel blok elde etmek için \% 0,5 konsantrasyonda prilokain kullanılmaktadır. \%0,5 konsantrasyon elde etmek için $5 \mathrm{ml} \% 2$ konsantrasyondaki prilokain (Priloc ${ }^{\circledR} \% 2$ ) ve $15 \mathrm{ml}$ \% 0,9 NaCl solüsyonu karıştırılmaktadır. Ultrason eşliğinde infraklavikular brakiyal pleksus bloğu 
uygulamasında yüksek frekanslı lineer ultrason probu (Mindray UMT200, Mindray Bio-Medical Electronics Co., Ltd. Shenzhen, PRC) ve 10 cm blok iğnesi (Stimuplex, Braun. Melsungen, Germany) kullanmaktadır. Ultrason probu infraklavikular bölgeye yerleştirilerek sagittal planda hastaların aksiller arteri görüntülendi. İşlem tek girişte üç enjeksiyon yapılarak uygulandı. Toplam lokal anestezik volümü üçe bölünerek posterior kord, medial kord ve lateral kordun etrafında dağılacak şekilde her üç korda eşit olarak verildi. Amaç, lokal anesteziğin bir yerde yüksek volümde toplanıp, etkilediği korddaki sinirlede motor bloğa neden olmamasıydı (Resim 1).

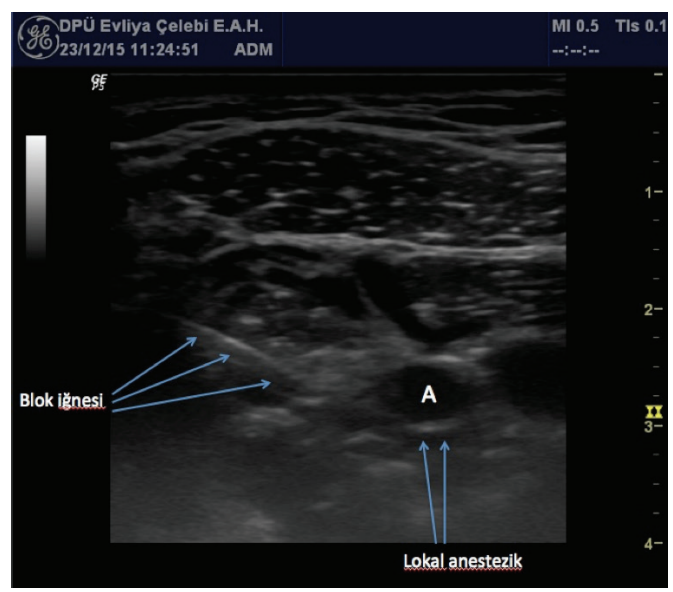

Resim 1. Ultrason eşliğinde diferansiyel infraklavikular blok uygulamasında lokal anestezik dağılımı, arter ve blok iğnesinin ultrason görüntüsü (A: Aksiller arter).

\section{Bloğun değerlendirilmesi:}

Hastaların takip formlarında kaydedilen duyusal blok ve motor blok skorları da değerlendirildi. Duyusal blok, 0 ile 2 arasında sayısal ölçek kullanılarak değerlendirildi (0: duyu yok, 1: dokunma duyusu, 2: ağrı). Motor blok, 0 ile 5 arasında sayısal ölçek kullanılarak değerlendirildi (0: Kontraksiyon yok, 1: Titreme 2: Yatay düzlemde hareket kabiliyeti, 3: Yerçekimine karşı hareket kabiliyeti 4: Kuvvete karşı direnç 5: Tam kas gücü). Fleksör ve ekstansör kasların motor hareketi ayrı ayrı incelendi. Eğer fleksör ve ekstansör kaslar arasında motor blok skoru açısından fark varsa daha düşük olan değer dikkate alındı.

Hastaların demografik verileri, blok uygulama endikasyonları, operasyon süresi, intraoperatif-postoperatif komplikasyon varlığı incelendi. Ayrıca blok başlangıç zamanı da değerlendirildi. Veri eksiği olan, yumuşak doku haricinde operasyon geçiren ve farklı dozda lokal anestezik uygulanan hastalar çalışma dışı bırakıldı. Peroperatif cerrah tarafında lokal anestezik infiltrasyonu yapılması, spontan solunumu baskılayan derin sedasyon ya da genel anesteziye geçilmesi durumunda blok başarısız olarak kabul edildi.

Çalışmaya ait değişkenlerin tanımlayıcı istatistikleri hesaplandı. Sürekli nicel veriler; n, ortalama, standart sapma, medyan, maksimum ve minimum olarak, nitel veriler ise n ve yüzdelik değerler olarak ifade edildi.

\section{Bulgular:}

Hasta kayıtlarının incelenmesiyle, toplam 53 adet ultrason eşliğinde diferansiyel üst ekstremite bloğu uygulanan hasta tespit edildi. 8 hasta eksik veri nedeniyle, bir hasta yumuşak doku haricinde

Sakarya Tip Dergisi 
Sakarya TIp Dergisi 2018;8(3):650-656

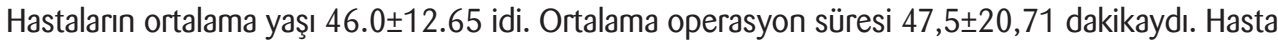
karekteristikleri Tablo 1 de özetlendi.

Tablo 1. Hasta karaktesistikleri. Veriler $n$, ortalama, standart sapma olarak verilmiştir.

\begin{tabular}{|c|c|}
\hline Hasta ve ameliyat özellikleri & Veriler \\
\hline Yaş (ort \pm ss) & $46.0 \pm 12.65$ \\
\hline Cinsiyet (K/E) & $(24 / 19)$ \\
\hline Operasyon süresi (orttss) & $47,5 \pm 20,71$ \\
\hline $\begin{array}{ll}\text { Operasyon (n): } & \text { Karpal tünel } \\
& \text { Tendon onarımı } \\
& \text { Ulnar sinir gevşetme } \\
& \text { Kitle eksizyonu }\end{array}$ & $\begin{array}{l}10 \\
11 \\
14 \\
8\end{array}$ \\
\hline
\end{tabular}

Diferansiyel brakiyal pleksus bloğu elde etmek için ortalama 19,53 $\pm 3,04 \mathrm{ml} \% 0.5$ konsantrasyonda prilokain kullanıldı. (Bir hastada $30 \mathrm{ml}, 3$ hastada $10 \mathrm{ml}$, geri kalan hastalarda $20 \mathrm{ml}$ ).

Ortalama blok başlangıç zamanı 20,76ะ7,56 dakika olarak bulundu.

Medyan (mininum-maksimum) motor blok skoru 3 (1-5) idi. 41 olguda motor fonksiyon yeterliydi, 2 olguda motor blok skoru 1 'di ve motor fonksiyon yeterli değildi.

43 hastanın 5 'inde blok başarısız kabul edildi. Bu hastaların birinde cerrah tarafından lokal anestezik infiltrasyonu yapilırken diğerlerinde propofol uygulamasıyla derin sedasyon ya da genel anestezi uygulandı. Geri kalan 38 hasta arasında 3 hastada intraoperatif ek sedasyon ihtiyacı oldu. Bu hastalarda spontan solunum korunarak, ikisine 50 pg intravenöz fentanil, birine 50 mg intravenöz ketamin yapıldı. Blok başarı oranı $\% 88$ olarak hesaplandı.

Olguların hiçbirinde allerjik reaksiyon, intraoperatif ve postoperatif komplikasyon gelişmedi. Diferansiyel blokla ilgili karakteristikler Tablo 2'de özetlendi.

Tablo 2. Diferansiyel brakiyal pleksus bloğu karakteristikleri. Veriler sayı, yüzde, ortalama, standart sapma, medyan, maksimum ve minimum olarak verilmiştir.

\begin{tabular}{|c|c|}
\hline ilaç ve Blok özellikleri & Veriler \\
\hline Prilokain miktarı (ort \pm ss) & $19,53 \pm 3,04$ \\
\hline Blok başlama zamanı (ort土ss) & $20,76 \pm 7,56$ \\
\hline Motor blok skoru Med (min-maks) & $3(1-5)$ \\
\hline Blok başarı oranı & $\% 88$ \\
\hline
\end{tabular}




\section{Tartışma:}

Bu çalışma, \% 0.5'lik konsantrasyonda prilokain kullanılarak, ultrason eşliğinde infraklavikular brakiyal pleksus bloğu ile diferansiyel bloğun mümkün olduğunu göstermektedir. Diferansiyel periferik sinir blokları, düşük dozlarda lokal anestetik kullanılmasına imkan sağlayan ultrason rehberliği kullanılarak mümkün olmuştur.

İntraoperatif olarak kas fonksiyonunu korumak, tendonların ve kas hareketlerinin gözlemlemek el ve ön kol cerrahisinde büyük önem taşır. Cerrahın işini oldukça kolaylaştırdığı gibi cerrahinin süresini de kısaltır. Bu, uyanık ve koopere bir hastayı gerektirir ve sadece geniş lokal anestezinin uygulanması yanı sıra bir diferansiyel (duyusal seçici/motor koruyucu) periferik sinir bloğunun uygulanmasıyla sağlanabilir. ${ }^{9,10}$

Diferansiyel blok tekniğinin en büyük avantajı, ameliyat sırasında aktif hareketleri olan ve koopere bir hastanın operasyonuna izin vermesidir. Özellikle tendon onarımı gibi işlemlerde, karpal tünel operasyonlarında ve basit el cerrahisinde bu blok oldukça faydalıdır. Cerrahın transfer için tendonun doğru gerilimini ayarlamasına yardımcı olur. Hastalar ameliyat sırasında parmağına istemli olarak fleksiyon-ekstansiyon yapabildiğinden, transfer edilen tendonun gerginliği ya da gevşekliği kontrol edilebilir. Ayrıca motor blok olmadığından erken mobilizasyona ve erken taburculuğa olanak tanır. ${ }^{9,10}$

Literatüre bakıldığında diferansiyel periferik sinir blokları ile ilgili çok az sayıda yayın olduğu görüldü. Sogbein ve ark. "motor koruyucu diz bloğu" olarak adlandırdıkları bir teknik geliştirmişlerdir. ${ }^{10}$ Ultrason eşliğinde adduktor kanal bloğu ile kombine edilen lateral femoral kutanöz sinir bloğu uygulayarak diz cerrahisinde motor blok oluşturmadan postoperatif analjezi sağlamışlardır. Motor koruyucu diz bloğu ile kuadriseps kas fonksiyonunu koruyarak postoperatif rehabilitasyona olanak tanınmıştır ve postoperatif daha uzun analjezi sağladığı bulundu. Bu blok için yazarlar toplam 60 $\mathrm{mL}$ toplam anestezik hacimde, $\% 0.5$ ropivakain, $2.5 \mathrm{mg} / \mathrm{mL}$ epinefrin uygulamışlardır. Tulgar ve ark. modifiye bir blok olan kostoklavikular yaklaşımla uyguladıkları brakiyal pleksus bloğu ile toplam $40 \mathrm{ml}$ lokal anestezik ( $20 \mathrm{ml} \% 0.5$ bupivakain $+10 \mathrm{ml} \% 2$ lidokain+10 $\mathrm{ml}$ serum fizyolojik) kullanarak üst ekstremitede diferansiyel blok elde etmişlerdir. ${ }^{11}$ Bizim çalışmamızdaki lokal anestezik dozları, bu yayınlarda belirtilen lokal anestezik madde dozuna göre oldukça düşüktü.

Kii ve ark. ise çalışmalarında el ve ön kol yumuşak doku cerrahisinde diferansiyel blok oluştumak için ultrason eşliğinde aksiller blok yaptllar. Diferansiyel blok elde etmek için gerekli olan ropivakain dozunun hesaplandığı çalışmada, \% 0,1285 konsantrasyonda $16 \mathrm{ml}$ ropivakainin aksiller bölgeden uygulanmasıya üst ekstremitede diferansiyel blok elde edilebileceği gösterildi. ${ }^{12}$ Missair ve ark. yaptıkları çalışmada $15 \mathrm{ml} \%$ 1,5 konsantrasyonda mepivakain ile ultrason eşliğinde supraklavikular blok uygulamışlardır. ${ }^{13}$ Bu dozda mepivakainin üst ekstremitede motor blok oluşturmadan cerrahi anestezi sağladığını bildirmişlerdir. Tüm bu çalışmalarda, düşük konsantrasyonda lokal anestezik kullanılarak diferansiyel blok elde edilebilceği görülmektedir.

Biz de diferansiyel blok elde etmek için kısa etki süresi ve düşük motor blok oluşturma potansiyeli nedeniyle \% 0,5 konsantrasyonda prilokain tercih ettik. Prilokain, periferal sinir blokları için yaygın olarak tercih edilen lokal anestetik değildir. Prilokain, ülkemizde ve Avustralya, Almanya, Büyük Britanya, Japonya gibi birçok ülkede periferik bölgesel bloklar için lisanslıdır. ${ }^{14}$ Prilokain, daha dü-
Sakarya Tip Dergisi

$2018 ; 8(3): 650-656$

BALABAN

Ultrason Eșliğinde Diferansiyel Üst Ekstremite Bloğu Deneyimlerimiz: Retrospektif Gözlemsel Araştırma 
Sakarya TIp Dergisi 2018;8(3):650-656 şük nörolojik veya kardiyak yan etki riski ile ilişkilidir. Akciğerde yüksek oranda emilime uğraması ve büyük miktarda dağılım nedeniyle düşük sistemik toksisiteye sahiptir. ${ }^{15}$ Methemoglobinemi oluşturma potansiyeli, prilokainin neden olabileceği başlıca endişelerden biridir. Vasters ve ark. Prilokain tarafından indüklenen methemoglobinemi ile ilişkili faktörleri belirtirken, yüksek dozda prilokainin methemoglobin oluşumu için en önemli belirleyici faktörlerden biri olduğunu ifade etmişlerdir. Bir sinir bloğu için kullanılan prilokain dozu ile maksimum methemoglobin miktari arasında pozitif bir korelasyon mevcuttur. ${ }^{15}$ Literatürde bildirilen maksimum güvenli prilokain dozu $4 \mathrm{mg} / \mathrm{kg}$ ile 8 $\mathrm{mg} / \mathrm{kg}$ arasında olup, maksimum doz 600 mg'dır. Tek doz 300-600 mg prilokainin ardından \% 15 civarında methemoglobin konsantrasyonları saptanabilir, bu normal sağlıklı yetişkinlerde zararsız kabul edilir. 70 kg'dan az olan bir birey için Birleşik Devletler Gıda ve illaç ídaresi (FDA) tarafından önerilen maksimum doz 4 mg/kg'dır. ${ }^{16}$ Olgularımızda kullandığımız Prilokain miktarı 100 mg idi ve methemoglobinemiye neden olabilecek dozların çok altındaydı. Hiçbir hastamızda siyanoz veya dispne, bulantı ve taşikardi gibi klinik semptomlar gözlemlemedik.

Prilokainin orta etki süresi ve düşük potensi, periferik sinir bloklarında kullanımını engelleyebilecek başka bir husustur. Fakat prilokainin hızlı etki başlangıçı bir lokal anestezik olması avantajdır. Prilokain ile oluşabilen motor blok süresinin düşük olması da bu lokal anesteziği diferansiyel bloklar için avantajlı hale getirir. Yapılan çalışmalarda da gösterilmiştir ki prilokain ile motor blok süresi ve ropivakaine göre anlamlı olarak daha kısadır. ${ }^{17}$ Frietag ve ark. aksiller blok ile brakiyal pleksus anestezisinin sağlanmasında prilokainin, ropivakaine göre duyusal ve motor blokajın daha hızlı başladığını göstermişlerdir. ${ }^{18} 40$ militre \% 1 Prilokain kullanıldığında duyusal bloğun median değerinin 163.5 dakika olduğunu ifade etmişlerdir. Bu süre basit el cerrahisi ve üst ekstremite yumuşak doku ameliyatlarında yeterlidir. Biz de çalışmamızdaki tüm hastalarda yeterli cerrahi anestezi süreleri elde ettik. Sonuç olarak; düşük dozda lokal anesteziğin ultrason eşliğinde uygulanması ile motor blok olmadan sensoryal blok elde edilebilir. Biz de \% 0,5 konsantrasyonda prilokain kullanılarak ultrason eşliğinde infraklavikular brakiyal pleksus bloğu ile üst ekstremitede başarılı diferansiyel (duyusal-seçici/ motor-koruyucu) blok elde ettik. Diferansiyel bloğun avantajı cerrahın kas ve tendon hareketlerini ameliyat sırasında gözlemleyebilmesidir. Bu durum özellikle tendon onarımında oldukça faydalıdır. Diferansiyel blok için, kullandığımız prilokainin avantajları hızlı başlangıç zamanına, kısa motor blok süresine, düşük kardiyak ve nörotoksik etkilere sahip olmasıdır. Basit el cerrahisi ve üst ekstremite yumuşak doku cerrahisinde prilokainin etki süresi yeterlidir. Dezavantajı ise kısa etki süresine sahip olması ve yüksek dozlarda uygulandığında methemoglobineniye neden olabilmesidir. Klinik olarak diferansiyel bloklarda uygulanan prilokain dozu methemoglobinemi yapan dozlara göre oldukça düşüktür. 
1. Reid D. Differential nerve block Can J Anaesth. 1998:45:1039-43

2. Preston R. Walking epidurals for labour analgesia: do they benefit anyone? Can J Anaesth. 2010;57:103-6.

3. Lalonde D, Martin A. Epinephrine in local anesthesia in finger and hand surgery: the case for wide-awake anesthesia. J Am Acad Orthop Surg. 2013;21:443-7.

4. Lalonde D, Martin A. Tumescent local anesthesia for hand surgery: improved results, cost effectiveness, and wide-awake patient satisfaction. Arch Plast Surg. 2014;41:312-6.

5. Takeda A, Ferraro LH, Rezende AH, Sadatsune EJ, Falcao LF, Tardelli MA. Minimum effective concentration of bupivacaine for axillary brachial plexus block guided by ultrasound. Braz J Anesthesiol. 2015;65:163-9.

6. McNaught A, Shastri U, Carmichael N, Awad IT, Columb M, Cheung), et al. Ultrasound reduces the minimum effective local anaesthetic volume compared with peripheral nerve stimulation for interscalene block. $\mathrm{Br}$ J Anaesth. 2011;106:124-30

7. Koköfer A, Nawratil J, Felder TK, Stundner O, Mader N, Gerner P. Ropivacaine $0.375 \%$ vs. $0.75 \%$ with prilocaine for intermediate cervical plexus block for carotid endarterectomy: A randomised trial. Eur J. Anaesthesiol. 2015;32:781-9

8. Freitag M, Zbieranek K, Gottschalk A, Bubenheim M, Winter R, Tuszynski $\mathrm{S}$, et al. Comparative study of different concentrations of prilocaine and ropivacaine for intraoperative axillary brachial plexus block. Eur J Anaesthesiol. 2006;23:481-6.

9. Lalonde $\mathrm{DH}$. Wide-awake extensor indicis proprius to extensor pollicis longus tendon transfer. Hand Surg Am. 2014;39:2297-9.

10. Sogbein OA, Sondekoppam RV, Bryant D, Johnston DF, Vasarhelyi EM, MacDonald S, et al. Ultrasound-Guided Motor-Sparing Knee Blocks for Postoperative Analgesia Following Total Knee Arthroplasty: A Randomized Blinded Study. J Bone Joint Surg Am. 2017;99:1274-1281.
11. Tulgar S, Ugutmen E. A modified technique for the application of ultrasound-guided costoclavicular brachial plexus block for elbow surgery leading to differential block. J Clin Anesth. 2018;47:65-66.

12. Kii N, Yamauchi M, Takahashi K, Yamakage M, Wada T. Differentia axillary nerve block for hand or forearm soft-tissue surgery. J Anesth. 2014;28:549-53.

13. Missair A, Osman BM, Palte HD, Gayer S, GutierrezJ, Gebhard RE. MotorSparing Surgical Nerve Blocks for Upper Extremity Surgery: Significantly Less Motor Paralysis Using $15 \mathrm{~mL}$ versus $30 \mathrm{~mL}$ of Mepivacaine $1.5 \%$ for Supraclavicular Block-A Prospective Randomized Double-Blinded Study. Orthop Muscular Syst 2017;6:231.

14. Marsan A, Kirdemir P, Mamo D, Casati A. Prilocaine or mepivacaine for combined sciatic-femoral nerve block in patients receiving elective knee arthroscopy. Minerva Anestesiol. 2004;70:763-9.

15. Vasters FG, Eberhart LH, Koch T, Kranke P, Wulf H, Morin AM. Risk factors for prilocaine-induced methaemoglobinaemia following periphera regional anaesthesia. Eur J Anaesthesiol. 2006;23:760-5.

16. Adams V, Marley J, McCarroll C. Prilocaine induced methaemoglobinaemia in a medically compromised patient. Was this an inevitable consequ ence of the dose administered? Br Dent J. 2007;203:585-7.

17. Janzen PR, Vipond AJ, Bush DJ, Hopkins PM. A comparison of 1\% prilocaine with $0.5 \%$ ropivacaine for outpatient-based surgery under axillary brachial plexus block. Anesth Analg. 2001;93:187-91

18. Freitag M, Zbieranek K, Gottschalk A, Bubenheim M, Winter R, Tuszynsk $S$, et al. Comparative study of different concentrations of prilocaine and ropivacaine for intraoperative axillary brachial plexus block. Eur J Anaest hesiol. 2006;23:481-6.

Sakarya Tıp Dergis

\section{BALABAN}

Ultrason Eşliğinde Diferansiyel Üst Ekstremite Bloğu

Deneyimlerimiz: Retrospektif Gözlemsel Araştırma 